\title{
Proton-linked L-fucose transport in Escherichia coli
}

\author{
Stuart A. BRADLEY, Colin R. TINSLEY, Jennifer A. R. MUIRY and Peter J. F. HENDERSON \\ Department of Biochemistry, University of Cambridge, Tennis Court Road, Cambridge CB2 1QW, U.K.
}

\begin{abstract}
1. Addition of L-fucose to energy-depleted anaerobic suspensions of Escherichia coli elicited an uncouplersensitive alkaline $\mathrm{pH}$ change diagnostic of $\mathrm{L}$-fucose $/ \mathrm{H}^{+}$symport activity. 2 . L-Galactose or $\mathrm{D}$-arabinose were also substrates, but not inducers, for the $\mathrm{L}$-fucose/ $\mathrm{H}^{+}$symporter. 3. L-Fucose transport into subcellular vesicles was dependent upon respiration, displayed a $\mathrm{pH}$ optimum of about 5.5, and was inhibited by protonophores and ionophores. 4. These results showed that L-fucose transport into $E$. coli was energized by the transmembrane electrochemical gradient of protons. 5. Neither steady state kinetic measurements nor assays of L-fucose binding to periplasmic proteins revealed the existence of a second L-fucose transport system.
\end{abstract}

\section{INTRODUCTION}

Escherichia coli grows on L-fucose (6-deoxy-L-galactose, Fig. 1) as sole carbon source. The cytoplasmic enzymes, L-fucose isomerase, L-fuculose kinase and Lfuculose-1-phosphate aldolase, have been purified and characterized (Green \& Cohen, 1956; Heath \& Ghalambor, 1962; Ghalambor \& Heath, 1962). The L-fucose transport and metabolic enzymes are regulated coordinately, and are induced during growth on L-fucose (Hacking \& Lin, 1976, 1977). We present evidence that the initial transport of L-fucose is coupled to the transmembrane electrochemical gradient of protons, $\Delta \mu_{\mathrm{H}^{+}}$. This gradient was postulated by Mitchell (1961, $1963,1973)$ to explain the energization of ATP synthesis and transport processes by the oxidoreductive reactions of respiration or photosynthesis (reviewed by Nicholls, 1982). The existence of $\Delta \mu_{\mathrm{H}^{+}}$across the bacterial cytoplasmic membrane has been substantially confirmed, the polarity being outside acid and positive (Harold, 1970; Ingledew \& Poole, 1984; Kagawa, 1978). In E. coli $\Delta \mu_{\mathrm{H}^{+}}$was shown to energize transport of lactose (West, 1970; West \& Mitchell, 1972; Flagg \& Wilson, 1977; Kaback, 1977), D-galactose (Henderson, 1974; Henderson et al., 1977; Horne \& Henderson, 1983), Larabinose (Henderson, 1974; Daruwalla et al., 1981) and D-xylose (Lam et al., 1980; Davis et al., 1984). Each of these sugars is transported by a separate, biochemically
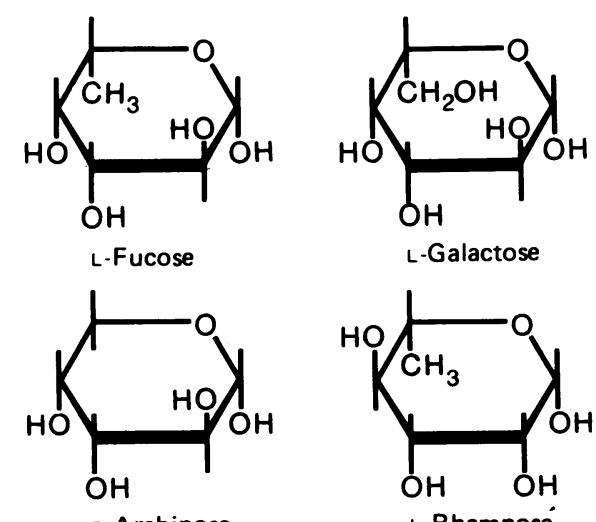

D-Arabinose

L-Rhamnosé

Fig. 1. Structural relationships of sugars similar to L-fucose

The $\beta$-form of each sugar is shown. and genetically distinguishable, transport system, with the common property of coupling inward sugar transport to uptake of protons, sugar $/ \mathrm{H}^{+}$symport [or the experimentally indistinguishable antiport of hydroxyl ions (Mitchell, 1973)].

\section{MATERIALS AND METHODS}

L-Fucose, L-galactose, D-arabinose, D-fucose, D-galactose, L-glucose, L-rhamnose, L-arabinose and L-mannose were obtained from Sigma Chemical Co. $\left[1-{ }^{3} \mathrm{H}\right]-\mathrm{L}-$ Fucose or $\left[1-{ }^{14} \mathrm{C}\right]-\mathrm{L}$-fucose were from Amersham International and were diluted with unlabelled L-fucose to give stock $2 \mathrm{~mm}$ solutions of specific radioactivity 1-5 $\mathrm{Ci} / \mathrm{mol}$.

E. coli strain JM2418 [ $\Delta$ (his gnd) $\Delta$ lac] was grown on basal salts medium (Henderson et al., 1977) supplemented with $10 \mathrm{~mm}$-L-fucose, $20 \mathrm{~mm}$-glycerol, and $80 \mu \mathrm{g}$ of $\mathrm{L}$ histidine $/ \mathrm{ml}$ with shaking at $30^{\circ} \mathrm{C}$. Culture volumes were $1-3 \mathrm{ml}$ in a $12 \mathrm{ml}$ test tube, $200 \mathrm{ml}$ in a $250 \mathrm{ml}$ conical flask, $400 \mathrm{ml}$ in a $500 \mathrm{ml}$ conical flask, or $1250 \mathrm{ml}$ in a 2 litre flask, for experiments investigating induction, energized transport into intact cells, sugar $/ \mathrm{H}^{+}$symport assay, or vesicle preparation, respectively. Right-sideout subcellular vesicles were made from spheroplasts (Witholt et al., 1976; Witholt \& Boekhout, 1978) by the method of Kaback (1972).

Unless indicated otherwise cultures of $E$. coli strain JM2418 were harvested, depleted of energy reserves, and washed as described by Henderson et al. (1977). For measurements of radioactive L-fucose transport into intact cells $150 \mathrm{~mm}-\mathrm{KCl} / 5 \mathrm{~mm}-\mathrm{Mes}(\mathrm{pH}$ 6.5) was the supporting medium, the assays being carried out with $10 \mathrm{~mm}$-glycerol plus aeration as described by Henderson et al. (1977). Transport of radioactive L-fucose $(80 \mu \mathrm{M})$ into subcellular vesicles in $50 \mathrm{~mm}$-potassium phosphate (pH 6.5)/10 mM- $\mathrm{MgSO}_{4}$ was energized by $20 \mathrm{~mm}$ ascorbate/0.1 mM-phenazine methosulphate plus oxygen and was measured as described by Horne \& Henderson (1983). Possible inhibitors were added to the suspensions $3 \mathrm{~min}$ before the labelled sugar.

Sugar-promoted $\mathrm{pH}$ changes (sugar $/ \mathrm{H}^{+}$symport) were measured with energy-depleted anaerobic suspensions of intact cells in $150 \mathrm{~mm}-\mathrm{KCl} / 2 \mathrm{mM}$-glycylglycine (pH 6.1-6.7) as detailed by Henderson \& Macpherson (1986). 


\section{RESULTS}

\section{$\mathrm{L}-\mathrm{Fucose} / \mathrm{H}^{+}$symport in $\boldsymbol{E}$. coli cells}

$E$. coli strain JM2418 was grown on glycerol plus Lfucose, harvested, depleted and resuspended as described (Henderson \& Macpherson, 1986). Addition of L-fucose to the anaerobic suspension elicited a rapid alkaline $\mathrm{pH}$ change followed by acidification (Figs. 2 and 3). The initial alkaline $\mathrm{pH}$ change was diagnostic of sugar $/ \mathrm{H}^{+}$ symport activity (West, 1970; West \& Mitchell, 1972), while the acidification was probably due to metabolism of L-fucose to acidic end-products (Hacking \& Lin, 1976, 1977). The initial rate and the extent of the proton influx (Table 1) was comparable with that described for other sugar $/ \mathrm{H}^{+}$symport systems in wild-type $E$. coli strains (West \& Mitchell, 1972; Henderson et al., 1977; Lam et al., 1980; Daruwalla et al., 1981).

The appearance of the alkaline $\mathrm{pH}$ change was abolished by reagents that render the membrane permeable to protons (Mitchell, 1961, 1970): $4 \mu \mathrm{M}$-tetrachloro-

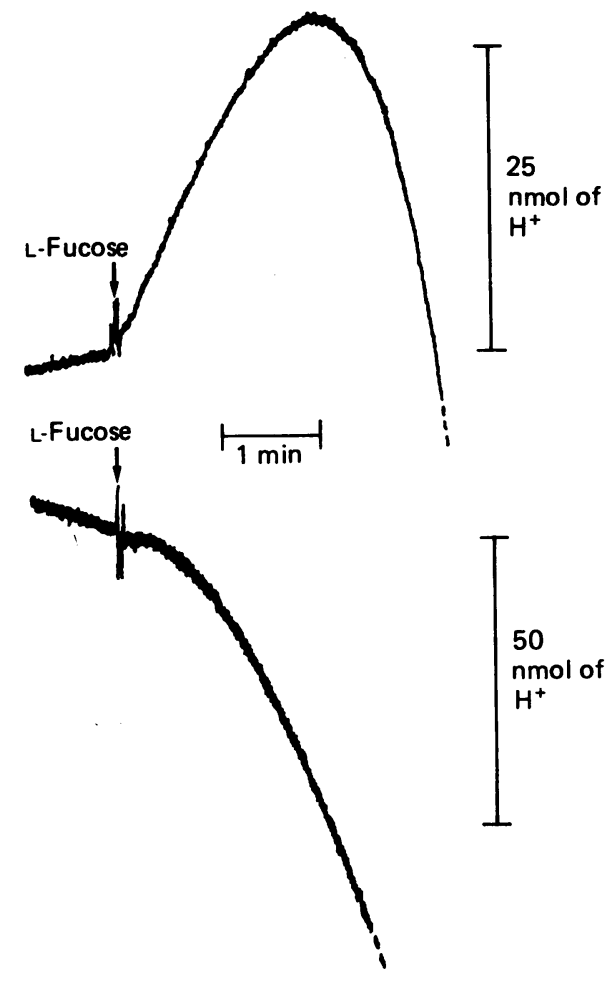

Fig. 2. Uncoupler-sensitive alkaline pH change promoted by L-fucose

E. coli strain JM2418 was grown on $20 \mathrm{~mm}$-glycerol +10 mM-L-fucose and additions as described in the Materials and methods section. The organisms were harvested and depleted as described by Henderson \& Macpherson (1986). In the two separate experiments shown $10 \mu \mathrm{mol}$ of $\mathrm{L}$ fucose was added to an anaerobic suspension of cells (17.3 mg dry mass) in $3.7 \mathrm{ml}$ of $150 \mathrm{~mm}-\mathrm{KCl} / 2 \mathrm{~mm}-$ glycylglycine, $\mathrm{pH}$ 6.24-6.34. The $\mathrm{pH}$ was measured as described by Henderson \& Macpherson and in Table 1 . An upward deflection represents an alkaline pH change. For the lower trace $15 \mathrm{nmol}$ of tetrachlorosalicylanilide was added $35 \mathrm{~min}$ before the $\mathrm{L}$-fucose. In a separate experiment (not shown) $4 \mu \mathrm{mol}$ of 2,4-dinitrophenol also prevented appearance of the L-fucose-promoted alkaline $\mathrm{pH}$ change.
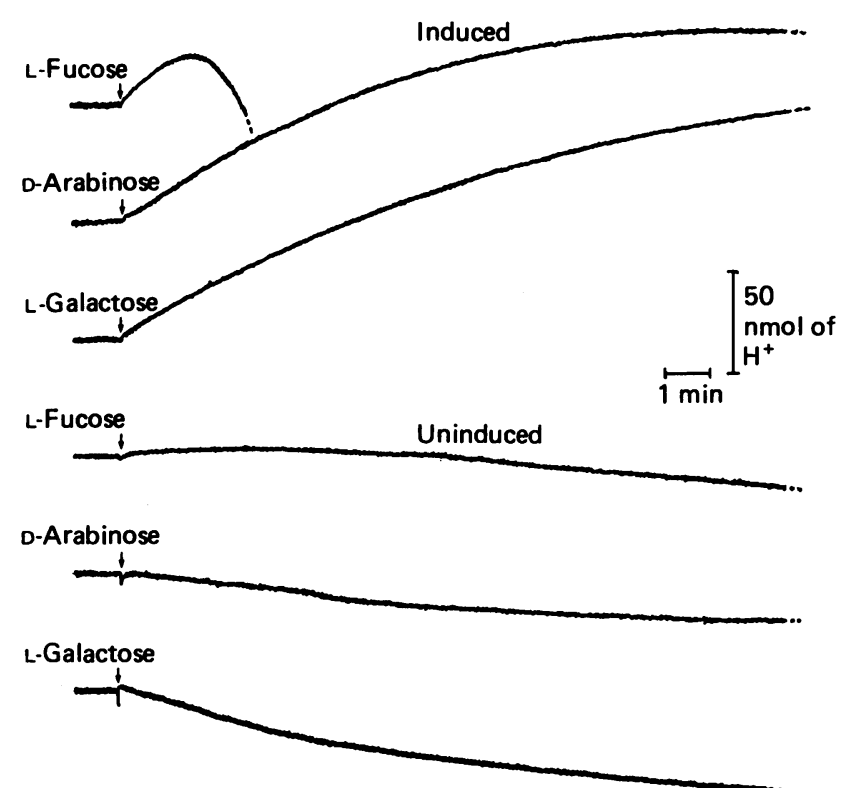

Fig. 3. Alkaline pH changes promoted by L-galactose and D-arabinose in $\mathrm{L}$-fucose-induced $E$. coli

Sugar-promoted pH changes were measured as described for Fig. 2 and Table 1. The top three traces used $E$. coli strain JM2418 (16.5 mg dry mass) originally grown on $20 \mathrm{~mm}$-glycerol $+10 \mathrm{~mm}$-L-fucose and the bottom three the same strain grown on $20 \mathrm{~mm}$-glycerol without L-fucose. The $\mathrm{pH}$ at the point of sugar addition was in the range 6.39-6.45. The calibration mark is the mean value from all the experiments.

salicylanilide (Fig. 2) or $1 \mathrm{~mm}$-2,4-dinitrophenol (results not shown). This indicated that the external $\mathrm{pH}$ change reflected a difference of $\mathrm{pH}$ across the membrane rather than a net change of $\mathrm{pH}$ inside and outside the cells.

The $\mathrm{pH}$ changes were absent from cells grown on glycerol alone (Table 1), confirming their association with L-fucose-inducible functions of transport or metabolism.

\section{Substrate specificity of the $\mathrm{L}$-fucose $/ \mathrm{H}^{+}$symport system}

L-Galactose and D-arabinose, which are structural analogues of L-fucose (Fig. 1), each elicited an alkaline $\mathrm{pH}$ change in experiments with L-fucose-induced $E$. coli strain JM2418 (Fig. 3). In neither case was a subsequent acidification observed (Fig. 3), consistent with the inability of wild-type $E$. coli strains to grow on either analogue, although mutations in the fuc operon permit growth on D-arabinose (LeBlanc \& Mortlock, 1971 $a, b$ ).

Neither L-galactose nor D-arabinose promoted a $\mathrm{pH}$ change when L-fucose was omitted from the growth medium (Fig. 2, Table 1), so their activity was associated with L-fucose-inducible functions. D-Fucose, L-glucose, L-rhamnose (6-deoxy-L-mannose), L-mannose, L-arabinose and D-xylose did not promote significant $\mathrm{pH}$ changes (Table 1). This confirmed that $\mathrm{L}$-fucose was not being transported by the other sugar $/ \mathrm{H}^{+}$symport systems for D-galactose, L-arabinose, or D-xylose (use of a lac mutant eliminated the lactose $/ \mathrm{H}^{+}$symport system), or on an $\mathrm{L}$ rhamnose $/ \mathrm{H}^{+}$symport system (T. Gunn, J. A. R. Muiry \& T. McDonald, unpublished work).

The average initial rates of $\mathrm{H}^{+}$uptake (mean \pm S.D. in $\mathrm{nmol} / \mathrm{min}$ per mg dry mass) were $1.05 \pm 0.38(1 \overline{4})$ for $\mathrm{L}$ - 
Table 1. Substrate specificity of sugar $/ \mathrm{H}^{+}$symport

$E$. coli strain JM2418 was grown on $20 \mathrm{mM}$-glycerol and $80 \mu \mathrm{g}$ of histidine/ml with or without $10 \mathrm{~mm}-\mathrm{L}$-fucose. The cultures were harvested, depleted of energy reserves and resuspended in $150 \mathrm{~mm}-\mathrm{KCl} / 2 \mathrm{mM}$-glycylglycine, $\mathrm{pH} 6.5$, as described by Henderson et al. (1977). Samples corresponding to about $17 \mathrm{mg}$ dry mass were resuspended under anaerobic conditions in $3.7 \mathrm{ml}$ suspensions, final $\mathrm{pH}$ 5.7-6.7. Each of the indicated sugars $(10 \mu \mathrm{mol})$ was added to one suspension and the subsequent $\mathrm{pH}$ change measured from the point of sugar addition to the point where the alkaline change ceased. The values were converted to $\mathrm{nmol}$ of $\mathrm{H}^{+}$using deflections produced by addition of $3 \mathrm{nmol}$ of $\mathrm{NaOH}$ (not shown in Fig. 2), correcting for any drift rate existing before addition of sugar. They are means of the indicated number of measurements, usually from more than one culture. Abbreviations: n.t., not tested.

Proton uptake (nmol of $\mathrm{H}^{+} / \mathrm{mg}$ dry mass)

\begin{tabular}{lcc}
\cline { 2 - 3 } Sugar & L-Fucose-induced & Uninduced \\
\hline L-Fucose & $* 1.2(14)$ & $* 0.1(8)$ \\
L-Galactose & $6.4(5)$ & $0.0(3)$ \\
D-Arabinose & $2.1(5)$ & $0.0(3)$ \\
L-Rhamnose & $0.0(2)$ & $0.0(3)$ \\
L-Arabinose & $0.0(3)$ & $0.0(4)$ \\
L-Glucose & $0.0(2)$ & $0.0(1)$ \\
D-Fucose & $0.0(3)$ & n.t. \\
D-Xylose & $0.0(2)$ & n.t.
\end{tabular}

* Rapid proton extrusion followed the proton uptake in the induced, but not the uninduced, cells.

Table 2. Specificity for inducer of $L$-fucose transport

E. coli strain JM2418 $(0.1 \mathrm{ml}$ in $2.5 \%$ nutrient broth) was inoculated into $1.5 \mathrm{ml}$ or $3 \mathrm{ml}$ of basal salts with $20 \mathrm{~mm}$ glycerol, $80 \mu \mathrm{g}$ of histidine $/ \mathrm{ml}$ and one of the indicated sugars (10 mM). After overnight growth to $A_{680} 0.7-1.7$ each culture was harvested by sedimentation and resuspended in the same volume of $150 \mathrm{~mm}-\mathrm{KCl} / 5 \mathrm{~mm}-\mathrm{Mes}$, $\mathrm{pH}$ 6.5. This washing procedure was repeated a further three times, and a final suspension $\left(A_{680} 1.0-1.9\right)$ was used for measurements of the initial rate of transport of $50 \mu \mathrm{M}$ L-fucose $\left({ }^{3} \mathrm{H}\right.$ - or ${ }^{14} \mathrm{C}$-labelled) energized by $10 \mathrm{mM}$-glycerol (see the Materials and methods section). Each value is the mean of at least four measurements on more than one culture expressed as a percentage of the mean value for the same cultures grown with L-fucose $(6-18 \mathrm{nmol} / \mathrm{min}$ per mg dry mass).

\begin{tabular}{lc}
\hline Sugar added & $\begin{array}{r}\text { L-Fucose transport } \\
\text { activity (\%) }\end{array}$ \\
\hline L-Fucose & 100 \\
L-Galactose & 2 \\
L-Arabinose & 3 \\
L-Rhamnose & 53 \\
L-Glucose & 3 \\
D-Fucose & 1 \\
D-Xylose & 7 \\
L-Xylose & 3 \\
L-Lyxose & 9 \\
L-Mannose & 5 \\
None & 4
\end{tabular}

fucose, $0.71 \pm 0.24$ (5) for L-galactose and $0.33 \pm 0.20$ (5) for $D$-arabinose, reflecting the relative substrate specificities at the concentration used.

\section{Inducer specificity of $\mathrm{L}$-fucose transport}

Transport of L-fucose into intact cells of $E$. coli is conveniently measured using the radioisotope-labelled sugar. When strain JM2418 was grown in the presence of different sugars, only cells grown with L-fucose or L-rhamnose displayed subsequent accumulation of $\mathrm{L}$ fucose (Table 2); L-galactose, D-arabinose, D-fucose, Lglucose or L-mannose were not effective inducers (Table 2). This was consistent with a previous observation that $D$-arabinose was not an inducer of the L-fucose operon in wild-type E.coli strains (LeBlanc \& Mortlock, 1971 $a, b$; Skjold \& Ezekiel, 1982). In E. coli and Klebsiella pneumoniae L-fuculose 1-phosphate was the true inducer rather than L-fucose (St. Martin \& Mortlock, 1976; Bartkus \& Mortlock, 1986). Therefore, the reason that Lgalactose and D-arabinose were not gratuitous inducers may be that they were not metabolized to the corresponding phosphorylated analogue of $\mathrm{L}$-fucose.

The unexpected induction of the $\mathrm{L}-\mathrm{fucose} / \mathrm{H}^{+}$transport system by L-rhamnose (Table 2 ) raised the possibility that $\mathrm{L}$-fucose $/ \mathrm{H}^{+}$symport occurred on an $\mathrm{L}$-rhamnose transport system (and vice versa). However, in experiments using L-fucose-induced cells, radiolabelled Lrhamnose was not accumulated significantly (results not shown), neither did L-rhamnose inhibit L-fucose transport (see Table 4), nor did it elicit an alkaline $\mathrm{pH}$ change (Table 1). The L-fucose and L-rhamnose transport systems are therefore different, and the induction of Lfucose transport by L-rhamnose probably reflects an ability of L-rhamnulose 1-phosphate to substitute for Lfuculose 1-phosphate.

\section{Steady state kinetics of $L$-fucose transport}

The initial rates of $\mathrm{L}$-fucose transport were measured over a wide range of substrate concentrations, $2-400 \mu \mathrm{M}$, at $\mathrm{pH}$ 6.5. Provided that the external concentration was not depleted by more than $15 \%$, the relationship between $v$ and $s$ was a rectangular hyperbola in three independent experiments, yielding apparent $K_{\mathrm{m}}$ values in the range $20-40 \mu \mathrm{M}$ and $V_{\max }$ of 9-30 $\mathrm{nmol} / \mathrm{min}$ per $\mathrm{mg}$ dry mass. The linearity of the reciprocal plots, one of which is shown in Fig. 4, was an important indication that only one L-fucose transport system was present.

\section{L-Fucose transport into subcellular vesicles of $\boldsymbol{E}$. coli}

Right-side-out subcellular vesicles made by the method of Kaback (1972) have been invaluable for studying the energization of substrate transport into micro-organisms (see, e.g., Kaback, 1972, 1974, 1976, 1977; Ramos et al., 1976; Ramos \& Kaback, 1977).

Radioisotope-labelled L-fucose was accumulated by such vesicles made from cells grown on L-fucose (Fig. 5, Table 3). The transport was critically dependent upon the presence of a respiratory substrate, ascorbate + phenazine methosulphate (Fig. 5) and was prevented by a respiratory inhibitor, cyanide (Table 3); respiration was necessary to generate $\Delta \mu_{\mathrm{H}^{+}}$(Ramos et al., 1976; Ramos \& Kaback, 1977). Even when respiratory substrate was present, transport of $L$-fucose was inhibited by protonophores (dinitrophenol and tetrachlorosalicylanilide) or ionophores [valinomycin or nigericin 


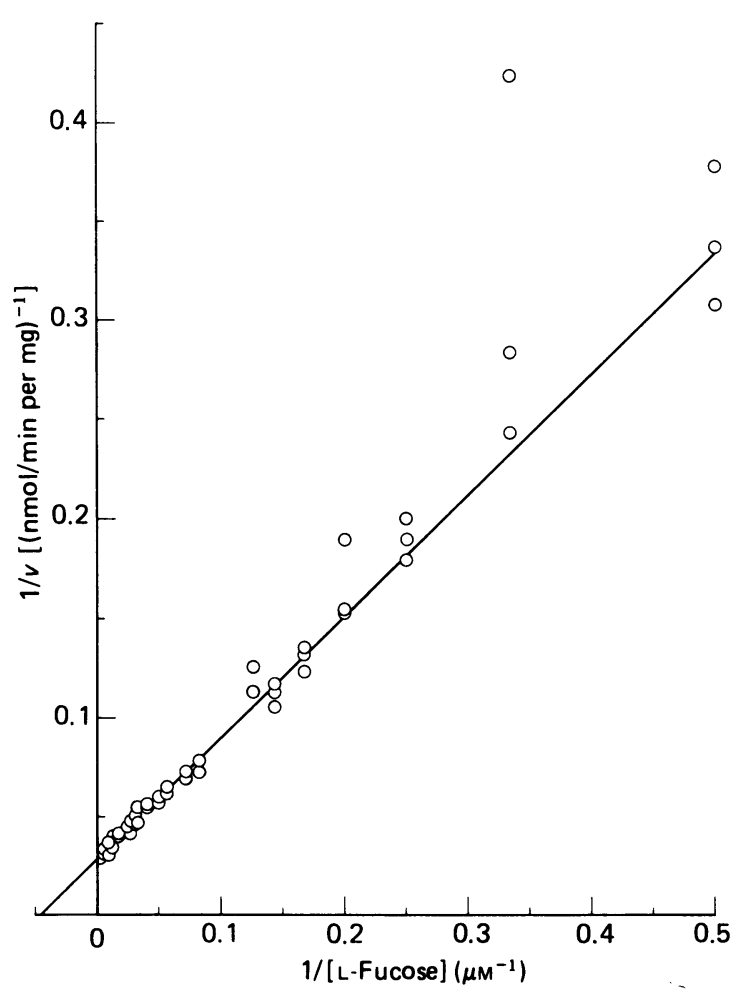

Fig. 4. Monophasic steady-state kinetics of $L$-fucose transport

$E$. coli strain JM2418 was grown on $20 \mathrm{mM}$-glycerol +10 mM-L-fucose, harvested and resuspended in $150 \mathrm{mM}-\mathrm{KCl} /$ $5 \mathrm{~mm}$-Mes, pH 6.5, +1 mM-mercaptoethanol for $1 \mathrm{~h}$ at $30^{\circ} \mathrm{C}$. The resedimented cells were resuspended in the same medium but without mercaptoethanol, sedimented again and finally resuspended to a density of $0.68 \mathrm{mg}$ dry mass $/ \mathrm{ml}$. Aerated samples $(0.2 \mathrm{ml})$ were incubated at $25^{\circ} \mathrm{C}$ for $3 \mathrm{~min}$ with $25 \mathrm{~mm}$-glycerol before addition of $50 \mu \mathrm{l}$ of $\left[1-{ }^{14} \mathrm{C}\right]-\mathrm{L}-$ fucose solution to give the indicated concentration range of $2-400 \mu \mathrm{M}$. After $15 \mathrm{~s} 0.2 \mathrm{ml}$ was filtered rapidly and washed twice with approx. $2 \mathrm{ml}$ of the above medium. The radioactivity trapped on the filter was measured and converted to nmol of sugar as described elsewhere (Henderson et al., 1977). At L-fucose concentrations below $8 \mu \mathrm{M}$ measurements were made in triplicate, and in duplicate above this concentration. The deduced $K_{\mathrm{m}}$ was $20.9 \pm 0.9 \mu \mathrm{M}$ and the $V_{\max }$ was $34.7 \pm 0.5$ $\mathrm{nmol} / \mathrm{min}$ per mg dry mass.

(Henderson, 1970; Harold et al., 1974)], compounds that discharge the protonmotive force (Fig. 5 and Table 3).

Maximum activity of the L-fucose transport system occurred at $\mathrm{pH} 5.5$, a value similar to the $\mathrm{pH}$ optimum for proton-linked lactose or galactose transport into subcellular vesicles (Ramos \& Kaback, 1977; Ramos et al. 1976; Horne \& Henderson, 1983). This corresponded closely to the $\mathrm{pH}$ dependence of the protonmotive force (Ramos et al., 1976). At pH 6.5 the average apparent $K_{\mathrm{m}}$ for L-fucose was in the range of $40-55 \mu \mathrm{M}$ with an average apparent $V_{\max }$ of about $4 \mathrm{nmol} / \mathrm{min}$ per $\mathrm{mg}$ of protein (data from three batches of vesicles).

Attempts to detect L-fucose-promoted $\mathrm{pH}$ changes in vesicles were not successful, possibly because this requires higher levels of transport activity achieved by amplifying gene expression (see, e.g., Daruwalla et al., 1981; Patel et al., 1982; Horne \& Henderson, 1983). Nevertheless,

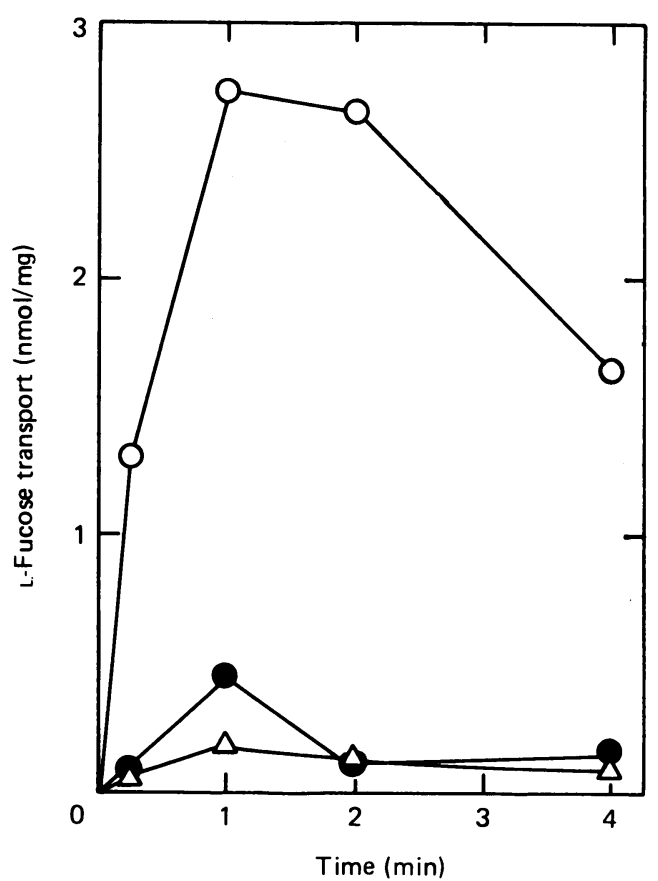

Fig. 5. Respiration-dependence and uncoupler-sensitivity of $\mathrm{L}$-fucose transport into subcellular vesicles of $\boldsymbol{E}$. coli

Subcellular vesicles were prepared from glycerol + Lfucose-grown cells of strain JM2418 and transport of $80 \mu \mathrm{M}$ radioisotope-labelled $\mathrm{L}$-fucose was measured as described by Horne \& Henderson (1983). O, Ascorbate/ phenazine methosulphate as respiratory substrate; $\mathbf{0}$, ascorbate/phenazine methosulphate $+1 \mathrm{~mm}$-2,4-dinitrophenol; $\triangle$, no additions. Each point is the mean of at least four measurements on at least two batches of vesicles.

these results all showed that L-fucose transport was linked to $\Delta \mu_{\mathrm{H}^{+}}$.

\section{Inhibition of L-fucose transport by sugars}

In order to substantiate the substrate specificity of the L-fucose transport system, the ability of unlabelled sugars to inhibit transport of radioactive L-fucose was measured using both intact cells and subcellular vesicles (Table 4). These results confirmed that L-galactose and D-arabinose were interacting with an L-fucose transport system; no significant interaction was observed with Lrhamnose, L-glucose, L-mannose, D-fucose or D-xylose. L-Galactose and D-arabinose were competitive inhibitors of L-fucose transport (J. A. R. Muiry, unpublished work).

\section{DISCUSSION}

The observation of an L-fucose-promoted alkaline $\mathrm{pH}$ change in intact cells, the dependence of $\mathrm{L}$-fucose transport into vesicles on respiration, and its sensitivity to uncoupling agents or ionophores confirmed the existence of an L-fucose $/ \mathrm{H}^{+}$symport system in E. coli. The possibility of L-fucose uptake by one of the other sugar $/ \mathrm{H}^{+}$symporters (for lactose, D-galactose, Larabinose, D-xylose or L-rhamnose) was eliminated by its occurrence in a lac deletion mutant, and by its different substrate and inducer specificities compared with galactose $/ \mathrm{H}^{+}$symport (Henderson et al., 1977; Henderson \& Giddens, 1977), xylose $/ \mathrm{H}^{+}$symport (Lam et al., 1980), 
Table 3. Effects of inhibitors and ionophores on energized $L$-fucose transport into subcellular vesicles

Transport of radioactive L-fucose $(40 \mu \mathrm{M})$ into right-sideout vesicles made from $E$. coli strain JM2418 grown on Lfucose plus glycerol was measured as described by Horne \& Henderson (1983) using $20 \mathrm{~mm}$-ascorbate $/ 0.1 \mathrm{~mm}$ phenazine methosulphate (PMS) and oxygen for energization. The indicated additions were made $3 \mathrm{~min}$ before the sugar. Each value is the mean of at least four measurements on more than one batch of vesicles expressed as a percentage of the initial rate obtained with L-fucose alone (3-9 $\mathrm{nmol} / \mathrm{min}$ per $\mathrm{mg}$ of protein). The controls contained an equivalent concentration of ethanol when this was a solvent for the compound added.

\begin{tabular}{lc}
\hline Addition & $\begin{array}{c}\text { L-Fucose transport } \\
\text { activity }(\%)\end{array}$ \\
\hline None & 100 \\
2,4-Dinitrophenol $(1 \mathrm{mM})$ & 7 \\
Tetrachlorosalicylanilide $(20 \mu \mathrm{M})$ & 11 \\
KCN $(4 \mathrm{mM})$ & 22 \\
Valinomycin $(4 \mu \mathrm{M})$ & 17 \\
Nigericin $(4 \mu \mathrm{g} / \mathrm{ml})$ & 31 \\
Unenergized control (ascorbate/PMS & 6 \\
omitted) &
\end{tabular}

Table 4. Inhibition of L-fucose transport by substrate analogues

Transport of radioisotope-labelled L-fucose was measured using washed suspensions of $\mathrm{L}$-fucose-induced $E$. coli strain JM2418 (Table 2) or right-side-out vesicles (Table 3 ). The indicated unlabelled sugar, $5.0 \mathrm{~mm}$ for the intact cells and $0.8 \mathrm{~mm}$ for the vesicles, was added to the incubation $3 \mathrm{~min}$ before the labelled $\mathrm{L}$-fucose. Each value is the mean of measurements of initial rate expressed as a percentage of the rate obtained with L-fucose alone in the same culture or batch of vesicles. At least four measurements on more than one preparation were made. Abbreviation: n.t., not tested.

\begin{tabular}{lcc}
\hline & \multicolumn{2}{c}{ Initial rate of L-fucose } \\
\cline { 2 - 3 } Sugar added & Intact cells & Vesicles \\
\hline & & \\
None & 100 & 100 \\
L-Fucose & 2 & 18 \\
L-Galactose & 9 & 44 \\
D-Arabinose & 29 & 105 \\
L-Rhamnose & 90 & 147 \\
L-Glucose & 94 & 162 \\
D-Fucose & 112 & 155 \\
D-Xylose & 102 & 167 \\
L-Mannose & 102 & 133 \\
D-Galactose & n.t. & 110 \\
D-Altrose & n.t. & 110
\end{tabular}

arabinose $/ \mathrm{H}^{+}$symport (Daruwalla et al., 1981) or Lrhamnose $/ \mathrm{H}^{+}$symport ( $\mathrm{T}$. Gunn, unpublished work). Hence there are at least six separate sugar $/ \mathrm{H}^{+}$symport systems in E. coli. A similar L-fucose $/ \mathrm{H}^{+}$symport was present in Salmonella typhimurium LT2, and in Klebsiella pneumoniae, but not in strains of Erwinia carotovora or Erwinia atroseptica (T. McDonald, unpublished work).

For each of the sugars D-galactose, L-arabinose and Dxylose there exists, in $E$. coli, a second transport system containing a binding protein (see, e.g. Boos, 1969; Brown \& Hogg, 1972; Schleif, 1969, Ahlem et al., 1982). These are not energized by $\Delta \mu_{\mathrm{H}^{+}}$, but by a phosphorylated product of glycolysis (see, e.g., Berger, 1973; Berger \& Heppel, 1974). We examined the possible existence of an L-fucose binding protein in L-fucose-induced $E$. coli strain JM2418 by extracting periplasmic proteins, concentrating them, and performing a binding protein assay with $1 \mu \mathrm{M}$ radioactive L-fucose using equilibrium dialysis as described by Clark \& Hogg (1981). No binding of Lfucose was detected. An identical procedure performed on D-xylose-induced cells clearly detected the xylose binding protein described by Ahlem et al. (1982). Arsenate $(20 \mathrm{~mm})$ inhibited the transport of $\mathrm{L}$-fucose $(50-200 \mu \mathrm{M})$ into intact cells by $30-50 \%$; generally, binding protein transport systems are inhibited 60-90\% by such arsenate concentrations and proton-linked systems are inhibited by 0-50\% (see, e.g. Berger, 1973; Berger \& Heppel, 1974; Daruwalla et al., 1981; Davis et al., 1984). The steady state kinetic plots were monophasic (Fig. 4). It therefore seemed unlikely that there was a second L-fucose transport system.

L-Galactose and D-arabinose will be useful alternative substrates for studying the L-fucose $/ \mathrm{H}^{+}$symport. The absence of acid extrusion (Fig. 3) showed that they were not metabolized completely, but they could still be substrates for the initial enzymes of $L$-fucose metabolism. Their failure to induce L-fucose transport was disappointing in view of the potential value of gratuitous inducers, but could be explained if they were not metabolized to the phosphorylated analogue of fuculose 1-phosphate, the inducer (Bartkus \& Mortlock, 1986). We obtained mutants impaired in L-fucose transport, but they also appeared to be defective in general expression of the L-fucose operon (see also Chakrabarti et al.,1984; Chen et al., 1983); this might be a consequence of there being only one transport system. Regulation of the L-fucose operon is an incompletely understood process, alteration of which enables $E$. coli to utilize D-arabinose (LeBlanc \& Mortlock, 1971 $a, b$; Skjold \& Ezekiel, 1982) or propanediol (Hacking \& Lin, 1976, 1977; Hacking et al., 1978; Boronat \& Aguilar, 1981).

However, the prime purpose of this work was an initial characterization of a different sugar $/ \mathrm{H}^{+}$symport system. Comparison of its similarities to, and differences from, other such systems in $E$. coli will aid elucidation of their molecular mechanism.

We thank the SERC for financial support through grant GR/D/22201. Mr. T. McDonald provided expert technical assistance.

\section{REFERENCES}

Ahlem, C., Huisman, W., Neslund, G. \& Dahms, A. S. (1982) J. Biol. Chem. 257, 2926-2931

Bartkus, J. M. \& Mortlock, R. P. (1986) J. Bacteriol. 165, 710-714

Berger, E. A. (1973) Proc. Natl. Acad. Sci. U.S.A. 70, 15141518 
Berger, E. A. \& Heppel, L. (1974) J. Biol. Chem. 249, 77477755

Boos, W. (1969) Eur. J. Biochem. 10, 66-73

Boronat, A. \& Aguilar, J. (1981) J. Bacteriol. 147, 181-185

Brown, C. E. \& Hogg, R. W. (1972) J. Bacteriol. 111, 606613

Chakrabarti, T., Chen, Y.-M \& Lin, E. C. C. (1984) J. Bacteriol. 157, 984-986

Chen, Y.-M., Lin, E. C. C., Ross, J. \& Aguilar, J. (1983) J. Gen. Microbiol. 129, 3355-3362

Clark, A. F. \& Hogg, R. W. (1981) J. Bacteriol. 147, 920-924

Daruwalla, K. R., Paxton, A. T. \& Henderson, P. J. F. (1981) Biochem. J. 200, 611-627

Davis, E.O., Jones-Mortimer, M. C. \& Henderson, P. J. F. (1984) J. Biol. Chem. 259, 1520-1525

Flagg, J. L. \& Wilson, T. H. (1977) J. Memb. Biol. 31, 233255

Ghalambor, M. A. \& Heath, E. C. (1962) J. Biol. Chem. 237, 2427-2433

Green, M. \& Cohen, S. S. (1956) J. Biol. Chem. 219, 557-568

Hacking, A. J. \& Lin, E. C. C. (1976) J. Bacteriol. 126, 1166 1172

Hacking, A. J. \& Lin, E. C. C. (1977) J. Bacteriol. 130, 832838

Hacking, A. J., Aguilar, J. \& Lin, E. C. C. (1978) J. Bacteriol. 136, $522-530$

Harold, F. M. (1970) Adv. Microb. Physiol. 4, 45-104

Harold, F. M., Altendorf, K. \& Hirata, H. (1974) Ann. N.Y. Acad. Sci. 235, 149-160

Heath, E. C. \& Ghalambor, M. A. (1962) J. Biol. Chem. 237, 2423-2426

Henderson, P. J. F. (1970) Annu. Rev. Microbiol. 25, 393428

Henderson, P. J. F. (1974) in Comparative Biochemistry and Physiology of Transport (Bolis, L., Bloch, K., Luria, S. E. \& Lynen, F., eds.), pp. 409-424, North-Holland Publishing Co., Amsterdam

Henderson, P. J. F. \& Giddens, R. A. (1977) Biochem. J. 168, 15-22

Henderson, P. J. F., Giddens, R. A. \& Jones-Mortimer, M. C. (1977) Biochem. J. 162, 309-320

Received 10 April 1987/24 June 1987; accepted 5 August 1987
Henderson, P. J. F. \& Macpherson, A. J. S. (1986) Methods Enzymol. 125, 387-429

Horne, P. \& Henderson, P. J. F. (1983) Biochem. J. 210, 699705

Ingledew, W. J. \& Poole, R. K. (1984) Microbiol. Rev. 48, 222-271

Kaback, H. R. (1971) Methods Enzymol. 22, 99-122

Kaback, H. R. (1972) Biochim. Biophys. Acta 265, 367-416

Kaback, H. R. (1974) Science 186, 882-892

Kaback, H. R. (1976) J. Cell. Physiol. 89, 575-593

Kaback, H. R. (1977) FEBS Symp. 42, 598-625

Kagawa, Y. (1978) Biochim. Biophys. Acta 505, 45-93

Lam, V. M. S., Daruwalla, K. R., Henderson, P. J. F. \& JonesMortimer, M. C. (1980) J. Bacteriol. 143, 396-402

LeBlanc, D. J. \& Mortlock, R. P. (1971a) J. Bacteriol. 106, 82-89

LeBlanc, D. J. \& Mortlock, R. P. (1971b) J. Bacteriol. 106, 90-96

Mitchell, P. (1961) Nature (London) 191, 144-148

Mitchell, P. (1963) Biochem. Soc. Symp. 22, 142-168

Mitchell, P. (1970) Symp. Soc. Gen. Microbiol. 20, 121-166

Mitchell, P. (1973) J. Bioenerg. 4, 63-91

Nicholls, D. G. (1982) Bioenergetics: An Introduction to the Chemiosmotic Theory, Academic Press, New York

Patel, L., Garcia, M. L. \& Kaback, H. R. (1982) Biochemistry 21, 5805-5810

Ramos, S., Schuldiner, S. \& Kaback, H. R. (1976) Proc. Natl. Acad. Sci. U.S.A. 73, 1892-1896

Ramos, S. \& Kaback, H. R. (1977) Biochemistry 16, 854-859

Schleif, R. (1969) J. Mol. Biol. 46, 185-196

Skjold, A. S. \& Ezekiel, D. H. (1982) J. Bacteriol. 152, 521523

St. Martin, E. J. \& Mortlock, R. P. (1976) J. Bacteriol. 127, 91-97

West, I. C. (1970) Biochem. Biophys. Res. Commun. 41, 655661

West, I. C. \& Mitchell, P. (1972) J. Bioenerg. 3, 445-462

Witholt, B., Boekhout, M., Brock, M., Kingma, J., Van Heerikhuizen, H. \& De Leij, L. (1976) Anal. Biochem. 74, 160-170

Witholt, B. \& Boekhout, M. (1978) Biochim. Biophys. Acta 508, 296-305 